\title{
UM PANORAMA DA \\ INTERNACIONALIZAÇÃO \\ DA EDUCAÇÃO SUPERIOR \\ NA ÁREA DO ENSINO \\ DE LÍNGUAS ADICIONAIS \\ E DA PESQUISA \\ NO BRASIL
}

\section{UN PANORAMA DE LA INTERNACIONALIZACIÓN DE LA EDUCACIÓN SUPERIOR EN EL ÁMBITO DE LA ENSEÑANZA DE LENGUAS ADICIONALES Y DE LA INVESTIGACIÓN EN BRASIL}

AN OVERVIEW OF INTERNATIONALIZATION OF HIGHER EDUCATION IN THE AREA OF ADITIONAL LANGUAGE TEACHING AND RESEARCH IN BRAZIL

Kleber Aparecido da Silva*

Universidade de Brasília

Rosely Perez Xavier**

Universidade Federal de Santa Catarina

\begin{abstract}
RESUMO: Nos dias atuais, quando as práticas sociais são dinâmicas e fluidas, a comunicação acontece de maneira complexa por intermédio das línguas e de uma diversidade de recursos semióticos e multimodais. Em face disso, a internacionalização para o ensino e para a pesquisa nas áreas de línguas se destaca moldando as trocas interacionais e interculturais. Neste contexto, o presente artigo, de (re)leitura crítica de literatura, aborda o conceito de internacionalização do/no ensino superior e o relaciona com o ensino e a pesquisa na área de línguas. O objetivo é evidenciar o panorama das ações de internacionalização no contexto brasileiro como preâmbulo necessário para apresentar os vários artigos que compõem este dossiê.
\end{abstract}

PALAVRAS-CHAVE: Ações de internacionalização. Ensino. Pesquisa. Linguística Aplicada.

\footnotetext{
* É Professor Associado do Programa de Pós-Graduação em Linguística da UnB e pesquisador colaborador do Programa de Pós-Graduação em Letras: Cultura, Educação e Linguagens da Universidade Estadual do Sudoeste da Bahia e do Programa de Pós-Graduaça em Letras, da Universidade Federal de Tocantins. E-mail: kleberaparecidodasilva@gmail.com.

** É Professora Titular Aposentada da UFSC e atua como colaboradora no Programa de Pós-Graduaça em Linguística da mesma universidade, na linha de pesquisa Ensino e Aprendizagem de Língua Estrangeira/ Segunda Língua. E-mail: roselyperezxavier@gmail.com.
} 
RESUMEN: En la actualidad, cuando las prácticas sociales son dinámicas y fluidas, la comunicación se produce de forma compleja a través de las lenguas y de una diversidad de recursos semióticos y multimodales. En vista de ello, la internacionalización en la enseñanza y la investigación en las áreas de lenguas se destaca por la configuración de intercambios interaccionales e interculturales. En este contexto, el presente artículo de (re)lectura crítica de la literatura aborda el concepto de internacionalización de/en la educación superior y lo relaciona con la enseñanza y la investigación en el área de lenguas. El objetivo es evidenciar el panorama de las acciones de internacionalización en el contexto brasileño como preámbulo necesario para presentar los diversos artículos que componen este dossier.

PALABRAS CLAVE: Acciones de internacionalización. Enseñanza. Investigación. Lingüística Aplicada.

ABSTRACT: Nowadays, when social practices are dynamic and fluid, communication happens in a complex way through languages and a diversity of semiotic and multimodal resources. In the light of this, internationalization for teaching and research in language areas stands out shaping international and intercultural exchanges. In this context, the present critical (re)reading of literature article addresses the concept of internationalization of/in higher education, and relates it to language teaching and research. The objective is to highlight the panorama of internationalization actions in the Brazilian context as a necessary preamble to present the various articles that make up this dossier.

KEYWORDS: Internationalization actions. Teaching. Research. Applied Linguistics.

\section{INTRODUÇÃO}

[...] O organismo age de acordo com sua estrutura [...] sobre seu ambiente; consequentemente, as mudanças produzidas no meio reagem sobre o organismo e sobre sua estrutura. O ser vivo vivencia, sofre as consequências de seu próprio comportamento. Essa ligação estreita entre a ação, o sofrer ou a vivência forma o que denominamos de experiência. (DEWEY 1980, p. 86, ênfase adicionada)

O presente artigo aborda a temática principal deste dossiê: internacionalização, e tem como objetivo discutir o seu conceito no contexto da educação superior e relacioná-lo às ações voltadas para o ensino e a pesquisa de línguas adicionais no campo da Linguística Aplicada. A importância de se discutir essa temática no contexto brasileiro, em particular, deve-se a uma política institucionalizada crescente de conhecimento e formação que vem se desenvolvendo na educação superior com experiências internacionais de aproximação, colaboração e solução de problemas entre aqueles envolvidos no ensino e na pesquisa, na superação das fronteiras geográficas.

As inúmeras políticas de internacionalização desenvolvidas nos contextos universitários brasileiros nos motivaram (organizadores deste dossiê e autores deste artigo) a fazer uma chamada de trabalhos sobre políticas e ações de internacionalização na educação superior para o ensino, a formação de professores/profissionais diversos e a pesquisa, tendo as línguas adicionais como estratégia para a realização dessas políticas e ações.

Iniciamos este artigo com uma breve discussão sobre o conceito de internacionalização e suas diferentes perspectivas. Na sequência, em seções distintas, relacionamos internacionalização com ações e estratégias para o ensino e a pesquisa no ensino superior. Finalizamos com a apresentação dos artigos que compõem este dossiê.

\section{INTERNACIONALIZAÇÃO: ABORDAGENS CONCEITUAIS E TEÓRICAS}

O debate em torno da internacionalização da educação superior é composto por um conjunto de conceituações que apresentam certas nuances, em determinados períodos e contextos, orientando políticas e práticas em nível nacional e institucional. 
Tradicionalmente, Knight (2003, p. 2) apresenta uma das definições mais difundidas de internacionalização, como sendo o "[...] processo de integrar uma dimensão internacional, intercultural ou global nos propósitos, funções ou serviços da educação superior”. Esse conceito busca apreender a realidade da globalização na qual a internacionalização ganhou amplas missões no meio educacional, com diversidade de tipos de formação e mudanças na sua relação com a sociedade.

Nessa mesma lógica, Hudzik (2011, p. 6) propõe o termo "internacionalização abrangente" (comprehensive internationalization) como um comprometimento firmado por ações que moldam o ethos e os valores de toda a instituição, afetando não só a vida no campus, mas também seus quadros de referência, parcerias e relações.

Outra definição presente nos dias atuais é a de "internacionalização em casa" (WACHTER, 2003), que se apresenta como o que acontece dentro do ambiente da instituição educacional especificamente, e está relacionada ao favorecimento da compreensão cultural e internacional nos processos de ensino e aprendizagem, nas atividades extracurriculares e nas relações com grupos locais e étnicos. No escopo dessa proposta, tem-se a internacionalização do currículo que, segundo Leask (2014), consiste no processo de ensino e aprendizagem pautado por conteúdos internacionalmente informados e diversificados, linguística e culturalmente, com o propósito de desenvolver perspectivas interculturais em todos os estudantes atendidos pela instituição educacional. Desse modo, contribui-se para a formação de cidadãos globais capazes de transformar a realidade local sem, necessariamente, investir em mobilidade internacional, a qual, por sua vez, beneficia apenas uma parcela dos estudantes.

A internacionalização educacional pressupõe um enfoque mais integral, baseado em processos, visando à melhoria sustentável da qualidade do ensino e das competências de funcionários e estudantes (DE WIT, 2011). Internacionalizar deveria ser uma construção transformadora da cultura de uma instituição. Contudo, é comum que a prática das instituições educacionais seja orientada por atividades instrumentais, fruto de ações individuais e desarticuladas, o que leva a grandes equívocos sobre a natureza desse processo. Para De Wit (2011), internacionalizar não é oferecer disciplinas ministradas em língua inglesa ou com conteúdo internacional; fazer da mobilidade acadêmica in (de recebimento) e out (de envio) atividade principal da internacionalização institucional; dispensar a avaliação das competências internacionais e interculturais por acreditar que elas serão naturalmente adquiridas pela comunidade acadêmica; nem supor que quanto maior a quantidade de parcerias, mais internacionalizada a instituição será; e, por fim, é equivocado, ainda, compreender internacionalização como um fim em si mesma, e não um meio para atingir um propósito.

Knight $(2011,2012)$ corrobora o pensamento de De Wit (2011) e acrescenta outros aspectos relevantes: o aprimoramento e o respeito ao contexto local sem querer dominá-lo; adaptabilidade às necessidades de cada instituição sem copiar modelos préfabricados; a busca por mensurar benefícios, riscos e consequências não intencionais, tais como a 'fuga de cérebros' ou a precarização dos serviços; e, finalmente, a visão de que globalização e internacionalização são processos distintos, porém associados.

Se, por um lado, a internacionalização da educação é produto da influência dos organismos, regiões e países ricos pautados no fenômeno da globalização, de outro, ela se serve da globalização como agente, potencialmente em prol da educação crítica, da troca de conhecimentos, da aquisição de línguas, do ensino e da pesquisa para o desenvolvimento humano, remetendo-nos a uma visão mais solidária, acadêmica e ética do processo (DE WIT, 2013a). Como produto da influência dos organismos, regiões e países ricos, a internacionalização se torna refém da falta de subsídio público e dos elevados padrões de competitividade. Nessa trilha, a internacionalização vai depender da reestruturação do Estado e da necessidade de providenciar o autofinanciamento das instituições educacionais com ampliação de mercado e de serviços (LIMA; CONTEL, 2011).

De forma geral, pensar em internacionalizar as instituições de ensino superior no Brasil tem se relacionado quase que naturalmente a aspectos positivos. O risco encontrado aqui é que, sem muitos questionamentos críticos, diversos agentes da internacionalização acabam por executar atividades da educação internacional como commodity, difundidas por organismos multilaterais, tais como a Organização para a Cooperação e Desenvolvimento Econômico (OCDE) e o Banco Mundial, sob a bandeira da internacionalização, sem reflexão sobre concretos ganhos para a qualidade educacional e a sua democratização (BRANDENBURG; DE WIT, 2011).

Brandenburg e De Wit (2011) escreveram sobre o fim da internacionalização no formato atual, em um chamamento público, para repensarmos as abordagens e redefinirmos processos socialmente mais justos. Knight (2011) também publicou um artigo 
questionando se a internacionalização havia 'perdido o seu caminho' (no original, lost its way). Nele, a autora indica que muitas instituições, ao se internacionalizarem, perderam o seu propósito inicial de cooperação, equidade e trocas, visando status e reconhecimento em um rol restrito e dominante do conhecimento, ou ainda, buscando recrutar o capital estrangeiro.

Stein (2019) aponta que essa guinada crítica dos principais teóricos da internacionalização foi um marco em direção à defesa de um processo mais ético e democrático. Para a autora, crescem os estudos da internacionalização crítica, cujo propósito é problematizar a visão politizada das abordagens de internacionalização da educação, que perpetuam padrões eurocêntricos de produção intelectual e que estabelecem relações neocoloniais e inequidades no acesso aos recursos.

A importância de estudos voltados para a internacionalização crítica está em suscitar reflexões sobre as ideologias políticas, sociais e econômicas subjacentes à relação entre o Norte e o Sul Global, que muitas vezes resulta em desigualdades quando um polo é marginalizado ou excluído pelo outro (VAVRUS; PEKOL, 2015). Para Stein (2019), precisamos orientar decisões públicas e estudos com vistas à: a) internacionalização para o bem público, em uma perspectiva liberal de formação humana; b) internacionalização para a solidariedade global, voltada para ações contra a opressão e a marginalização das culturas e indivíduos que, de fato, possam mudar o status quo vigente; e, c) internacionalização decolonial, capaz de promover mudanças em políticas e práticas vindouras.

Em nosso entendimento, a internacionalização da educação, concebida por um viés crítico, apresenta-se como uma estratégia de mudança e de justiça social em contextos educacionais de países em desenvolvimento como o Brasil. Para tanto, uma vez que a linguagem possibilita ao indivíduo estabelecer relações sociais e culturais, bem como exercer o seu poder de agência diante de situações opressoras naturalizadas, as línguas e suas respectivas políticas linguísticas assumem, neste contexto, papel determinante. É sobre as políticas linguísticas que a próxima seção se debruça.

\section{INTERNACIONALIZAÇÃO DO/NO ENSINO SUPERIOR}

Embora o processo de internacionalização do ensino superior no Brasil seja um movimento recente (CARVALHO; ARAÚJO, 2020), pode-se dizer que esse processo já vinha se constituindo gradativamente na vida acadêmica, pelo menos no que se refere às políticas linguísticas.

Como ambientes internacionais (CARVALHO; ARAÚJO, 2020), as universidades brasileiras sempre receberam estudantes estrangeiros em seus programas de graduação e pós-graduação com direito a cursos intensivos, ou em módulos, de português para estrangeiros. Da mesma forma, iniciativas governamentais previamente consolidadas, como o Programa de Estudantes-Convênio de Pós-Graduação (PEC-PG) ${ }^{1}$, criado oficialmente em 1981, e o Programa de Leitorado², regulamentado desde 1999, ambos promovidos pela CAPES em parceria com o Ministério das Relações Exteriores, ajudaram a incrementar políticas linguísticas para o ensino de português como língua estrangeira tanto no Brasil como no exterior. Para De Wit (2013b), essas ações poderiam ser denominadas de "educação internacional" por se referirem a um conjunto fragmentado de atividades internacionais.

Em 2011, como parte de uma política governamental de internacionalização do ensino superior, foi criado o Programa Ciência sem Fronteiras (CsF), na gestão da Presidenta Dilma Rousseff. Foi uma iniciativa que "promoveu imersão cultural, aprofundamento em idiomas, experiências internacionais, oportunidades de estágios e inserção de estudantes com [médio] e baixo poder aquisitivo” (ALVES; AZEVEDO, 2019, p. 7). O programa consistiu em bolsas de estudos no exterior para estudantes de graduação e pós-

1 PEC-PG é um programa que oferece bolsas de mestrado e doutorado para candidatos de países com os quais o Brasil possui acordo de cooperação cultural e/ou educacional para a sua realização em instituições brasileiras de ensino superior (MINISTÉRIO DAS RELAÇÕES EXTERIORES, [2020?]).

2 O Programa de leitorado financia professores interessados em divulgar a cultura brasileira em instituições universitárias estrangeiras (CAPES, 2020). 
graduação $^{3}$ de áreas prioritárias e estratégicas para o desenvolvimento do Brasil, visando à "consolidação, expansão e internacionalização da ciência e tecnologia, da inovação e da competitividade brasileira por meio do intercâmbio e da mobilidade internacional", como aponta o site do Programa CsF (PORTAL CIÊNCIA SEM FRONTEIRAS, 2021). Ainda com base nas informações desse site, até janeiro de 2016, foram implementadas 92.880 bolsas, sendo 79\% delas atribuídas à modalidade de Graduação Sanduíche no Exterior.

Em um estudo sobre o Programa CsF, Conceição (2017) avaliou o desempenho de ex-bolsistas no Exame Nacional de Desempenho dos Estudantes (ENADE) e comparou-o com o obtido por dois outros grupos de estudantes: os que também realizaram intercâmbio acadêmico internacional por meio de outras iniciativas e os não intercambistas. Com base em testes estatísticos, os resultados mostraram que os ex-bolsistas do Programa CsF apresentaram melhores notas em relação aos demais grupos, tanto na parte de formação geral como no componente específico.

Como ação integrada ao Programa CsF, em 2012 foi instituído o Programa Inglês sem Fronteiras “[...] com o objetivo de propiciar a formação e capacitação de alunos de graduação das instituições de educação superior para os exames linguísticos exigidos para o ingresso nas universidades anglófonas” (BRASIL, 2012). Em 2014, esse programa foi substituído pelo 'Idiomas sem Fronteiras' (IsF), ampliando a capacitação de acadêmicos, professores e técnico-administrativos das instituições de educação superior, públicas e privadas, em outras línguas adicionais (incluindo o português), assim como de professores de línguas estrangeiras da rede pública de educação básica, "[...] conferindo-lhes a oportunidade de novas experiências educacionais e profissionais voltadas para a qualidade, o empreendedorismo, a competitividade e a inovação" (BRASIL, 2014).

As ações empreendidas para o Programa IsF tiveram forte impacto no interior das instituições de educação superior com a expansão da oferta de cursos de línguas adicionais (inglês, francês, italiano entre outras), visando ao aperfeiçoamento linguístico dos estudantes, professores e técnico-administrativos. Nesta época, uma das iniciativas do Ministério da Educação (MEC) foi lançar o curso gratuito My English Online (MEO) para o mesmo público-alvo de instituições cadastradas ao IsF-Inglês e para professores da educação básica. O curso era dividido em cinco níveis: iniciante, básico, pré-intermediário, intermediário e avançado, sendo esse último preparatório para três exames de proficiência: Cambridge English Advanced (CAE), Cambridge English First (FCE) e TOEFL, conforme Portal do MEC (2017).

Ainda como política de governo, entre 2011 e 2014, a Secretaria de Educação Profissional e Tecnológica (SETEC/MEC) buscou implementar ações de internacionalização voltadas para a educação profissional (SELL, 2020). Para isso, a proposta foi ampliar a oferta de cursos de línguas adicionais para melhor qualificar a comunidade escolar dos Institutos Federais, resultando na criação de cursos de idiomas por EaD, ofertados pela Rede Federal de Educação Profissional, Científica e Tecnológica.

Baseado em Vieiras (2016), Sell (2020, p. 95) explica que os Institutos Federais do Ceará (IFCE), Rio Grande do Norte (IFRN), sul do Rio Grande do Sul (IFSul) e o Fórum dos Assessores de Relações Internacionais (FORINTER), em trabalho conjunto, elaboraram os projetos pedagógicos dos cursos de espanhol, inglês e português para estrangeiros na modalidade a distância, compondo o Programa e-Tec Idiomas sem Fronteiras.

Todas essas iniciativas visaram complementar e fortalecer o Programa CsF, que exerceu "[...] papel central no avanço das políticas linguísticas e no processo de internacionalização das universidades" (ALVES; AZEVEDO, 2019, p. 7). No entanto, em 2016, na gestão do Presidente Michel Temer, o Programa foi descaracterizado em seus objetivos e metas, como explica Alves e Azevedo (2019), para conceder bolsas a alunos de baixa renda do ensino médio de instituições públicas para realizarem cursos de idiomas no exterior. Em 2017, o Programa foi finalizado em virtude da situação econômica e política do país.

3 O público-alvo também envolveu “[...] estudantes de cursos técnicos, docentes, pesquisadores, especialistas, técnicos, tecnólogos e engenheiros, pessoal técnicocientífico de empresas e centros de pesquisa e de inovação tecnológica brasileiros, para o desenvolvimento de projetos de pesquisa, estudos, treinamentos e capacitação em instituições de excelência no exterior." (BRASIL, 2011). 
Embora tenha se concentrado na mobilidade estudantil, o Programa CsF foi, indubitavelmente, um marco importante na política de ações de internacionalização do ensino superior, considerando os seus objetivos para o país e o seu grande alcance na formação e qualificação de estudantes, professores e pesquisadores.

A internacionalização da educação superior vem se desenvolvendo para atender não somente a mobilidade estudantil dentro de um sistema de cooperação interinstitucional, mas também a abertura de oportunidades de estágio, a diminuição de barreiras linguísticas, o desenvolvimento do ensino, da pesquisa e extensão, e a formação de parcerias para pesquisas de interesse comum (CARVALHO; ARAÚJO, 2020).

Na próxima seção, abordaremos a pesquisa como meta no processo de internacionalização.

\section{INTERNACIONALIZAÇÃO DA PESQUISA}

No ensino superior, o locus da produção e da circulação do conhecimento científico está associado aos programas de pós-graduação, embora esse conhecimento possa ser produzido sem qualquer vínculo formal com esses programas.

Com o apoio da política nacional de Ciência e Tecnologia, determinada pelos Planos Nacionais de Pós-graduação (PNPG), a internacionalização da pesquisa vem se constituindo como meta. É o que o documento elaborado pela Comissão Especial de acompanhamento do PNPG 2011-2020 (BRASIL, 2017a) projetou e recomendou para o quinquênio 2016-2020 por meio de ações mobilizadoras. Destacamos algumas: "apoio às parcerias institucionais internacionais estratégicas entre Universidades brasileiras e estrangeiras"; "estímulo às cooperações e redes entre IES nacionais e estrangeiras"; "suporte institucional para a mobilidade dos programas sanduíche"; "intercâmbio de pesquisadores" e a presença de pesquisadores brasileiros no exterior, bem como a visita de pesquisadores altamente qualificados ao país (BRASIL, 2017a, p. 22-24).

Ainda como recomendação, o documento vislumbra a "[...] modernização curricular da graduação, em consonância e integração com cenários internacionais" e "editais de contratação de docentes estrangeiros" (BRASIL, 2017a, p. 23). Segundo Silva-Júnior e Kato (2018, p. 30), para além de uma condução acadêmica, o PNPG é uma política de Estado, pois prevê alterações legislativas ao propor a contratação de pesquisadores estrangeiros, o que resultaria em reformas na política trabalhista brasileira, e também a indução pedagógica ao propor currículos que se adequem ao contexto "internacional", resultando em programas de ensino que seriam delineados diretamente pelas pró-reitorias de graduação, pesquisa e pós-graduação das universidades, submetendo os professores a ensinar conteúdos estabelecidos externamente.

Há ainda ações que incidem diretamente no "plano geopolítico". Em outras palavras, o documento prevê ações de internacionalização pautadas não somente "na busca de conhecimentos em países mais adiantados", mas também na "cooperação solidária com nações amigas" no apoio ao desenvolvimento de seus quadros científicos e tecnológicos” (BRASIL, 2017a, p. 26). Nesse sentido, o Brasil se coloca em posição estratégica na geopolítica internacional. Na área de políticas linguísticas, essas cooperações já vêm sendo realizadas por programas de pós-graduação em Linguística e em Educação, particularmente com países do continente africano.

Com base nessas ações, cabe aqui indagar: Que tipo de parceria está sendo construída com os agentes que participam do complexo e dinâmico processo de internacionalização? Essa construção leva em consideração uma perspectiva crítica e decolonial? A nosso ver, as políticas públicas de internacionalização da pesquisa no Brasil deveriam se pautar na reflexão dessas questões.

Em 2017, outro documento importante foi publicado pelo MEC com dados sobre a situação e os projetos de internacionalização das instituições de ensino superior com programas de pós-graduação avaliados pela Capes com nota de 3 a 7. Os dados foram coletados por meio de um questionário encaminhado às instituições com o objetivo de subsidiar a Capes na criação de um novo programa que pudesse aperfeiçoar o processo de internacionalização, tanto nas instituições em estágio mais avançado nesse processo, como naquelas em fase incipiente (BRASIL, 2017b). Os resultados mostraram que o modelo predominante é a 
internacionalização passiva, com baixas taxas de atração de profissionais internacionais e que "[...] a forma como o conhecimento obtido fora do país está sendo difundido e aproveitado internamente tem deixado a desejar" (BRASIL, 2017b, p. 45).

Ainda com base neste documento, o novo programa a ser desenvolvido e implementado pela Capes teria que prever a inclusão de "treinamento em língua estrangeira para bolsistas antes de deixarem o país, assim como preparação em termos culturais e práticas [sic] para o intercâmbio" (BRASIL, 2017b, p. 45). Esta ação coloca a educação linguística a serviço de outras áreas, assim como fazia o CsF, e sugere o desenvolvimento da competência intercultural do intercambista. Além disso, conforme o documento, o programa teria que exigir clara mobilidade ativa para atrair e fixar pesquisadores estrangeiros no Brasil e, consequentemente, produção científica conjunta.

Para incrementar essas ações nos programas de pós-graduação, a Capes lançou, ainda em 2017, o Programa Institucional de Internacionalização (Capes-PrInt) por meio de edital, com início em novembro/2018 e término marcado para novembro/2022. O programa tem por objetivo reforçar as ações projetadas e algumas delas recomendadas pela Comissão Especial de acompanhamento do PNPG 2011-2020 (BRASIL, 2017a), e considerar os resultados dos questionários sobre a situação da internacionalização nas instituições de ensino superior (BRASIL, 2017b), a saber:

i) fomentar a construção, a implementação e a consolidação de planos estratégicos de internacionalização das instituições contempladas nas áreas do conhecimento por elas priorizadas; ii) estimular a formação de redes de pesquisas internacionais com vistas a aprimorar a qualidade da produção acadêmica vinculadas à pósgraduação; iii) ampliar as ações de apoio à internacionalização na pós-graduação das instituições contempladas; iv) promover a mobilidade de docentes e discentes, com ênfase em doutorandos, pós-doutorandos e docentes para o exterior e do exterior para o Brasil, vinculados a programas de pós-graduação stricto sensu com cooperação internacional; v) fomentar a transformação das instituições participantes em um ambiente internacional; vi) integrar outras ações de fomento da CAPES ao esforço de internacionalização. (BRASIL, 2017 c, p. 1-2)

Como requisito para concorrer a esse edital, está a inserção de materiais, temas e disciplinas em língua estrangeira na estrutura curricular dos programas de pós-graduação envolvidos no projeto institucional, implicando clara indução na condução políticopedagógica nesses programas.

Concordamos com Silva-Júnior e Kato (2018, p. 30-31) quando afirmam haver dois momentos no processo de internacionalização da educação superior e da pós-graduação brasileira:

Há uma primeira em que a predominância acadêmica local se põe sobre a dimensão nacional em sua relação com a academia mundializada. Contudo, o que se apresenta como segundo momento inverte as predominâncias, pretendendo, na condição de política de Estado, articular uma política de internacionalização mundial mais homogeneizada. Isto é, poder-se-ia falar em uma mundialização da política de internacionalização da pós-graduação. Analisando com atenção os documentos e seus critérios, é possível afirmar que há uma divisão entre a universidade de ensino e a universidade de pesquisa (as famosas Research Universities nos Estados Unidos), além de uma divisão e hierarquização das instituições no país e fora dele. Isto indica a existência de uma divisão internacional do trabalho acadêmico-científico bastante similar à divisão internacional do trabalho que se realiza na economia, sob a hegemonia do capital financeiro no âmbito da mundialização do capital. (SILVA-JÚNIOR; KATO, 2018, p. 30-31)

Como buscar uma hipótese explicativa para a inversão da lógica da internacionalização da pesquisa como sugerem Silva-Júnior e Kato? Somente compreendendo e investigando o contexto maior, buscando as forças centrípetas e centrífugas que (inter)faceiam este contexto complexo e dinâmico, a partir de uma perspectiva crítica e decolonial, e com uma predisposição de ouvir os que deveriam ser atores/protagonistas na (re)construção de uma política de internacionalização para a pesquisa, ou seja, alunos de pósgraduação e professores/pesquisadores que atuam neste locus profissional. 
A nosso ver, é necessário que vejamos as políticas de internacionalização de forma crítica e decolonial para o fortalecimento da pesquisa no Brasil. Para exemplificar, algumas pesquisas têm sido realizadas nesta direção no campo da Linguística Aplicada Crítica, visando trazer evidências sobre como a ecologia das relações e do saber é construída no processo de internacionalização em diferentes instituições educacionais. Pazello (2019), por exemplo, investigou como o conceito de internacionalização é percebido em uma universidade federal e como ele se reflete na instituição, enfocando a emergência do contexto linguístico-pedagógico docente e suas características. Os resultados mostraram uma internacionalização ainda passiva, corroborando os resultados encontrados no documento do MEC (BRASIL, 2017b). Essa internacionalização gira em torno da mobilidade acadêmica, que incorpora o sentido de educação como serviço prestado para atender as demandas do mercado neoliberal, e que considera a língua inglesa, juntamente com o professor dessa língua, como essenciais para a realização das ações. Entretanto, para a autora, essas evidências podem ser ressignificadas por epistemologias do pluralismo, as quais colocam a diversidade como inerente a todas as interações e estimulam a educação linguística.

Outro exemplo é a pesquisa de Leal (2020), que buscou compreender as bases epistemológicas dos discursos dominantes de internacionalização. Os dados, também gerados no contexto de uma universidade federal, sugerem que a internacionalização é substantiva na instituição, devido ao seu papel estratégico e institucionalizado, que legitima a racionalidade funcional, alicerçada em percepções e interesses previamente fixados. Constatou-se uma perspectiva reducionista de internacionalização que não reconhece o âmbito regional e local, e que reforça a dicotomia Norte-Sul e os problemas sociais latentes. A investigação possibilitou identificar uma dimensão hegemônica colonial em torno do que seja (ou não) internacionalizar, bem como problematizar as abordagens convencionais de internacionalização. Logo, outras possibilidades de internacionalização da educação superior pública brasileira são necessárias, particularmente as que possam idealizar perspectivas desvinculadas da racionalidade dominante e que considerem futuros alternativos.

\section{CONSIDERAÇÕES FINAIS}

O panorama aqui apresentado sobre a internacionalização do ensino e da pesquisa no Brasil com enfoque na área de línguas adicionais encontra maior espaço de discussão nos artigos que compõem este dossiê. São doze trabalhos voltados para aspectos diferenciados, porém interligados, do movimento de internacionalização: políticas educacionais linguísticas, ações institucionais estratégicas, proficiência linguística, percepções sobre internacionalização, pedagogias, interculturalidade, educação profissional e formação de professores.

O dossiê inicia com Guimarães e Pereira, que analisam um corpus de pesquisas acadêmicas que tratam da internacionalização da educação na sua interface com políticas linguísticas, no período entre 2009 e 2019. Os autores buscam apontar tendências e lacunas visando contribuir com o avanço da ciência nesta área do conhecimento.

Na sequência, Pinto, Garcia e Santos apresentam ações desenvolvidas na Universidade Estadual Paulista, instituição multicampi, para aprimorar a proficiência linguística em línguas estrangeiras da comunidade acadêmica. Da mesma forma, Pereira relata as ações criadas pela Universidade Federal da Bahia para responder a esse mesmo desafio, de modo a preparar a comunidade interna para a mobilidade internacional e outras metas alinhadas à internacionalização.

Cordeiro, Baldin e Albuquerque, por sua vez, discutem as ações empreendidas pelo Português sem Fronteiras, articuladas ao Programa de Extensão Universitária de Português para Falantes de Outras Línguas da Universidade Tecnológica Federal do Paraná, campus Curitiba. Ainda no campo dos estudos referentes aos programas de internacionalização da língua portuguesa, Santos e Sarmento analisam os editais de seleção de professores do Programa de Leitorado para avaliar a política educacional linguística definida pelo governo federal para a atuação do profissional que trabalhará com o ensino de português como língua adicional no exterior.

Krause-Lemke e Puh fazem uma análise de estudos voltados para as línguas eslavas, conduzidos por docentes do Programa de Pósgraduação em Educação da Universidade do Centro-Oeste do Paraná (Unicentro) e do Núcleo de Estudos Eslavos. As autoras 
ressaltam que, em virtude das parcerias com universidades de países como Polônia, Ucrânia, Sérvia, Croácia e Montenegro, e de outras ações de internacionalização, seria necessário redimensionar esse movimento nas universidades para também acolher o conhecimento científico produzido sobre essas línguas.

Considerando as percepções dos agentes envolvidos no processo de internacionalização, Bührer investiga a visão de professores e gestores de uma comunidade universitária sobre as vantagens, desvantagens e os desafios no uso do inglês como meio de instrução. Por outro lado, Guimarães, Mendes e Hildeblando Junior analisam as percepções de alunos do Programa IsF sobre a internacionalização.

Na esteira da pedagogia, Silva e Santos comparam uma aula gamificada com uma aula não gamificada para avaliar a motivação dos acadêmicos do Programa IsF, da Universidade Federal de Sergipe.

No trabalho de Schaefer, o foco reside nas representações culturais que permeiam os processos interativos no teletandem, contexto telecolaborativo de aprendizagem de línguas estrangeiras. O autor discute como representações culturais estereotipadas foram superadas no contexto investigado.

No campo da educação profissional, Silva e Ramos apresentam um diagnóstico da competência oral em inglês de recepcionistas de hotel como estratégia para ações de endomarketing, que favoreçam a formação linguística desses profissionais.

Considerando a formação de professores num processo de “internacionalização em casa”, Freitas, Brossi e Rosa-da-Silva discutem as percepções de professores de inglês sobre os Encontros de Educação de Professores de Línguas Estrangeiras, realizados na Universidade Estadual de Goiás. Esses encontros visaram promover a reflexão e o aprimoramento da competência comunicativa, linguística e pedagógica desses professores.

Todos esses trabalhos contribuem para a contextualização do movimento de internacionalização do ensino superior no Brasil, para a compreensão do fenômeno e para o desenvolvimento do conhecimento científico, teórico e pedagógico. Por isso, convidamos você a ler os trabalhos e a refletir sobre eles.

\section{REFERÊNCIAS}

ALVES, Y. V.; AZEVEDO, M. A. O fim do Programa Ciência sem Fronteiras como parte do processo de recessão das politicas educacionais de ensino superior no Brasil. Disponível em: https://coloquioep.com.br/anais/trabalhos/linha1/submissao29.pdf. Acesso em: 22 fev. 2021.

BRANDENBURG, U.; DE WIT, H. The end of internationalization. International Higher Education. n. 62, p. 15-17, 2011. Disponível em: https://ejournals.bc.edu/index.php/ihe/article/view/8533. Acesso em: 20 jul. 2020.

BRASIL. Ministério da Educação. Portaria Normativa $n^{\circ}$ 1.466, de 18 de dezembro de 2012. Institui o Programa Inglês sem Fronteiras. Disponível em: http://isf.mec.gov.br/images/pdf/portaria normativa_1466 2012.pdf. Acesso em: 12 fev. 2021.

BRASIL. Ministério da Educação. Portaria Normativa $n^{\circ}$ 973, de 14 de novembro de 2014. Institui o Programa Idiomas sem Fronteiras, 2014. Disponível em: http://isf.mec.gov.br/images/pdf/novembro/Portaria 973 Idiomas sem_Fronteiras.pdf.Acesso em: 12 fev. 2021.

BRASIL, Ministério da Educação. Fundação Capes. Relatório final 2016/2017 da Comissão Especial de Acompanhamento do PNPG: Brasília, DF: Capes, 2017a. Disponível em: https://www.gov.br/capes/pt-br/centrais-de-conteudo/231117-relatorio-pnpg-final2016-cs-pdf. Acesso em: 14 fev. 2021. 
BRASIL, Ministério da Educação. Ministério da Educação. Fundação Capes. A Internacionalização da Universidade Brasileira: resultados do questionário aplicado pela Capes. Brasília, DF: Diretoria de Relações Internacionais, out. 2017b. Disponível em: https://www.gov.br/capes/pt-br/centrais-de-conteudo/a-internacionalizacao-nas-ies-brasileiras-pdf. Acesso em: 14 fev. 2021.

BRASIL, Ministério da Educação. Fundação Capes. Programa Institucional de Internacionalização - Capes-PrInt. Edital n. 41/2017c. Disponível em: https://www.gov.br/capes/pt-br/centrais-de-conteudo/10112017Edital412017InternacionalizacaoPrInt2.pdf. Acesso em: 14 fev. 2021.

BRASIL. Decreto n 7.642, de 13 de dezembro de 2011. Institui o Programa Ciência sem Fronteiras. Diário Oficial da União. Seção 1,

2011, p. 239. Brasília. Disponível em:

https://pesquisa.in.gov.br/imprensa/jsp/visualiza/index.jsp?jornal=1\&pagina=7\&data=14/12/2011. Acesso em: 26 mar. 2021 .

CAPES. Programa Leitorado. 2020. Disponível em: https://www1.capes.gov.br/bolsas-e-auxilios-internacionais/pais/218multinacional/10088-programa-leitorado. Acesso em: 26 mar. 2021.

CARVALHO, S. B. R.; ARAÚJO, G. C. Gestão da internacionalização das instituições de ensino superior. Avaliação (Campinas), v. 25, n. 1, 2020, p. 113-131. Disponível em: https://www.scielo.br/pdf/aval/v25n1/1982-5765-aval-25-01-113.pdf. Acesso em: 22/02/2021.

CONCEIÇÃO, O. C. Uma avaliação do Programa Ciência sem Fronteiras: efeitos sobre desempenho, trancamento e conclusão. 2017. 70f. Dissertação (Mestrado em Economia do Desenvolvimento) - Faculdade de Administração, Contabilidade e Economia, Pontifícia Universidade Católica do Rio Grande do Sul, Porto Alegre, 2017.

DEWEY, J. Experiência e natureza. São Paulo: Abril Cultural, 1980.

DE WIT, H. Internationalization of higher education: nine misconceptions. International Higher Education, n. 64, p. 1-6, 2011. Disponível em: https://ejournals.bc.edu/index.php/ihe/article/view/8556/8321. Acesso em: 20 jul. 2020.

DE WIT, H. Misconceptions about (the end of) internationalization. University World News. 2013a. Disponível em: https://www.universityworldnews.com/post.php?story=2014071611562927. Acesso em: 20 jul. 2020.

DE WIT, H. Repensando o conceito da internacionalização. Ensino Superior. Unicamp, paginação irregular, 2013b. Disponível em: https://www.revistaensinosuperior.gr.unicamp.br/international-higher-education/repensando-o-conceito-dainternacionalizacao. Acesso em: 14 fev. 2021.

HUDZIK, J. Comprehensive internationalization: from concept to action. Washington, D.C: NAFSA (Association of International Educators), 2011.

KNIGHT, J. Updated internationalization definition. International Higher Education, n. 33, p. 2-3, 2003. Disponível em: https://doi.org/10.6017/ihe.2003.33.7391. Acesso em: 14 ago. 2020.

KNIGHT, J. Has internationalization lost its way? In: The Observatory on Borderless Higher Education. Borderless 2011: perspectives on the future. 2011. p. 10. Disponível em: http://www.obhe.ac.uk/documents/view details?id=864. Acesso em 20 jul. 2020 .

KNIGHT, J. Cinco verdades a respeito da internacionalização. Ensino Superior. Unicamp, paginação irregular, 2012. Disponível em: https://www.revistaensinosuperior.gr.unicamp.br/international-higher-education/cinco-verdades-a-respeito-dainternacionalizacao. Acesso em: 18 mar. 2014. 
LEAL, F. G. Bases epistemológicas dos discursos dominantes de 'internacionalização da educação superior' no Brasil. 2020. Tese (Doutorado em Administração) - Centro de Ciências da Administração e Socioeconômicas, Universidade do Estado de Santa Catarina, Florianópolis, 2020.

LEASK, B. Internationalizing the curriculum and all students' learning. International Higher Education, v. esp., n. 78, p. 5-6, 2014. Disponível em: https://doi.org/10.6017/ihe.2014.78.5798. Acesso em: 14 ago. 2020.

LIMA, M. C.; CONTEL, F. B. Internacionalização da educação superior: nações ativas, nações passivas e a geopolítica do conhecimento. São Paulo, SP: Alameda, 2011.

MEC. Assessoria de Comunicação Social. Abertas inscrições para o curso de inglês My English Online, 2017. Disponível em: http://portal.mec.gov.br/component/tags/tag/39041-my-english-online. Acesso em: 26 mar. 2021.

MINISTÉRIO DAS RELAÇÕES EXTERIORES. Programa de Estudantes-Convênio de Pós-Graduação - PEC-PG. 2021. Disponível em: http://www.dce.mre.gov.br/PEC/PECPG.php. Acesso em: 26 mar. 2021.

PAZELLO, E. Internacionalização na UTFPR-CT: da cereja do bolo às duas pontas do iceberg. 2019. Tese (Doutorado em Letras) Setor de Ciências Humanas, Universidade Federal do Paraná, Curitiba, 2019.

PORTAL CIÊNCIA SEM FRONTEIRAS. O que é?. Disponível em: http://www.cienciasemfronteiras.gov.br/web/csf/oprograma;jsessionid=FD84968E831836B9D4D9AB523DDB48B6. Acesso em: 26 mar. 2021.

SELL, S. A dimensão comunicativa e cultural do material de ensino a distância de PLA do Programa e-Tec Idiomas Sem Fronteiras. 2020. Tese (Doutorado em Linguística) - Universidade Federal de Santa Catarina, Florianópolis, 2020.

SILVA-JÚNIOR, J.; KATO, F. B. G. A política de internacionalização da pós-graduação stricto sensu brasileira: breves considerações sobre a atual política da Capes. In: FERREIRA, V. A. (org.). Políticas e avaliação da pós-graduação stricto sensu: da inserção social local à internacionalização. Brasília: Cátedra UNESCO de Juventude, Educação e Sociedade, Universidade Católica de Brasília, 2018. p. 17-36.

STEIN, S. Critical internationalization studies at an impasse: making space for complexity, uncertainty, and complicity in a time of global challenges. Studies in Higher Education, v. 44, n. 1, p. 1-14, 2019. Disponível em: http://doi.org/10.1080/03075079.2019.1704722. Acesso em: 16 jul. 2020.

VAVRUS, F.; PEKOL, A. Critical internationalization: moving from theory to practice. FIRE - Forum for International Research in Education, v. 2, n. 2, p. 5-21, 2015. Disponível em: https://doi.org/10.18275/fire201502021036. Acesso em: 16 jul. 2020.

VIEIRAS, D. B. Português como língua adicional (PLA): módulos 1 e 2. Apresentação de slides. Pelotas: Núcleo de Idiomas IFSul (NIDI), 2016.

WACHTER, B. An introduction: internationalisation at home in context. Journal of Studies in International Education, v. 7, n. 1, p. 5-11, 2003.

\section{()(1) $\circledast \circledast$}

Recebido em 22/02/2021. Aceito em 02/03/2021. 